\title{
Postgraduate Writing: A New Frontier for Writing Pedagogy
}

The writing of postgraduate students has emerged in the past two decades as a new frontier for writing pedagogy. This frontier has been developed in the English for Specific Purposes (Dudley-Evans and St. John, 1998; Hutchinson and Waters, 1987) and English for Academic Purposes (Hyland, 2006; Jordan, 1997; Swales, 1990) areas of applied linguistics and writing studies, especially in relation to postgraduate students for whom English is not the first language. The number of these students has grown exponentially in the last 50 years, and they are now the majority in many fields at many universities. The large number of writers for whom English is an additional language coupled with the number of first-language English writers whose academic writing skills are not sufficient for writing papers or theses ${ }^{1}$ in specialist areas emphasizes the need for attention to postgraduate writing and pedagogy.

In addition to ESP and EAP orientations to language and curriculum, a primary research orientation informing pedagogy in postgraduate writing has been corpus linguistics (Biber, Conrad, and Reppen, 1998), the study of texts in digitized form, especially collections of these into large databases of electronic corpora. Digitized texts can be quickly searched for specific words, phrases, or constructions, by the method of concordancing and other methods, and these can be sorted into lists and categories (e.g. based on word frequency or neighboring words) and displayed in different ways. Textual analysis by computer has often been supported and supplemented by systemic functional linguistics (Halliday, 1985), a linguistic approach that has become mainstream for applied language studies outside the United States. Both corpus linguistics and systemic functional linguistics have contributed substantially to our knowledge of the genre conventions and forms of spoken and written English: see, for example, the text-based analyses of Eggins (1994); Biber, Conrad, and Leech (2002); Biber, Johansson, Leech, Conrad, and Finegan (1999); and Carter and McCarthy (2006). A different approach to disciplinary discourse is that of scholars in the United States working in the Writing in the Disciplines [WID] (e.g. Carter, 2007) and Writing Across the Curriculum [WAC] (e.g. Segal and Smart, 2006) orientations, which have had a strong pedagogical focus primarily at undergraduate level. 
Both the British and the American traditions have emphasized the varying genre conventions and writing needs of scholars in different disciplines, differences which are continuing to evolve in the most advanced forms of specialized writing, i.e. theses and published scholarly articles and books. The results of investigations of writing in specific disciplines are accumulating, as can be seen by a review of published research in writing journals - especially in English for Specific Purposes and to a lesser extent in CCC (College Composition and Communication), Journal of English for Academic Purposes, Journal of Second Language Writing, and Written Communication - as well as in disciplinary journals, many of which are starting to analyze their own genre conventions and the communicative needs of their students and practitioners. With the ongoing specialization of fields, discipline-specific writing at postgraduate level has become an increasingly complex and challenging area of writing to handle in terms of effective pedagogy (see Swales and Feak, 1994, and Hyland, 2006, for useful texts).

\section{Editor's Perspective on Volume 1, Number 2}

The current issue of Writing \& Pedagogy is an attempt to address some of the issues of interest in the teaching of writing, particularly thesis writing, at postgraduate level. The issue grew out of a research project that I initiated at the University of Luton (now Bedfordshire) with my award as a U.K. National Teaching Fellow of $£ 50,000$ from the U.K. Institute of Teaching and Learning (HEFCE) to develop support for postgraduate students and their supervisors (www.thesisweb.org). A number of the authors of this issue were participants in the project, including Ylva Berglund Prytz, Caroline Coffin, Jim Donohue, Phil Hubbard, Oliver Mason, and Vladimir Žegarac. The Research Matters articles by Coffin and by Donohue, the Reflections on Practice article by Hubbard, and the From the eSphere article by Mason and myself are the direct result of work on the project using analyses of $\mathrm{PhD}$ theses selected by professors in five fields as model theses. The article by Berglund Prytz is also related to project work, and the book reviewed in this issue is by another project member, Dimitra Koutsantoni. Other project members were Lawrence Lau (University of Luton) and Tony McEnery (Lancaster University). The other two articles (by Suganti P. John and by Annette Frances Sachtleben, Pat Strauss, and Elizabeth Turner) were solicited through a Call for Papers.

The project was in response to the common problem faced at universities that disciplinary specialists who instruct postgraduate students and supervise them in writing their theses generally do not offer - and often do not want or feel qualified to offer - either the type or the amount of feedback that students feel they need. This problem, which stems from a misunderstanding of disciplinary

\section{eevinoxonline}


knowledge as apart from its construction and expression through language, is exacerbated by a second misconception - that writing is a general skill with high transfer across contexts. Universities (both administrators and scholars) have been slow to recognize the extent to which specific writing skills are tied to specific writing contexts and purposes; and they have been even slower to accept that the degree of transfer of writing skill - and indeed the possibility, in the first place, for developing writing skill - is limited in a generalized or decontextualized approach to academic writing. At postgraduate level, there is the additional "catch" that teachers of writing usually do not have the disciplinary knowledge required to teach or comment in depth on theses or other scholarly writing outside their own field, while disciplinary specialists do not have the linguistic awareness or pedagogical techniques required to teach writing as part of the content of their discipline. Universities have failed to appreciate the knowledge gap on both sides and the inherent paradox of "[the] conception of the disciplines as domains of specialized content knowledge... [together with] the assumption that a writing course outside the disciplines could somehow improve students' writing in the disciplines" (Carter, 2007: 386). Addressing the paradox calls for new knowledge and practices on both sides of this disciplinary/writing pedagogy gap. Hence the current issue of Writing \& Pedagogy.

This issue contains three data-based Research Matters articles which offer detailed analysis and discussion of postgraduate theses with pedagogical recommendations for students and their thesis supervisors or instructors. In particular, they address matters of authorial voice and stance towards other writers and sources situating the research. Two of the research articles are based on the same model $\mathrm{PhD}$ thesis in Film Studies, on the genre of the Western movie. In providing detailed functional systemic analyses of a thesis in a relatively new discipline which, like literary studies, is highly discursive and critical, this pair of articles makes a unique contribution to the literature on academic writing. In the first of these, Caroline Coffin examines two chapters of the Film Studies thesis in detail to show how the thesis writer interweaves her own voice and point of view with those of other authors and sources of knowledge. In the second of the articles on the model thesis, James Donohue considers how the Film Studies thesis preface, which stands in for the larger category that includes a thesis introduction, frames and projects the entire thesis. In the last article in the Research Matters section, Suganthi P. John considers the functions of the first person pronoun in establishing author identity in a thesis.

Coffin's article, "Incorporating and Evaluating Voices in a Film Studies Thesis," has the pedagogical purpose of showing the different ways a doctoral student can incorporate and evaluate sources as different voices supporting

\section{eevinoxonline}


the argument and research of the student's thesis. Coffin analyzes all forms of referencing within two chapters of the model Film Studies thesis, setting her analysis within a discussion of the conventions of referencing within Film Studies and other disciplines. She draws on appraisal theory to show how the writer positions herself within her field and topic in relation to different authors and themes through her referencing and citation strategies. Coffin compares her findings to those of Hyland (2000) for "soft sciences" fields, noting many differences, such as a high use of direct quotation rather than summary or paraphrase and of direct reference to authors by name within the citing sentence rather than in parenthetical or footnoted references. She highlights the indirect way in which the author builds a persuasive argument, through selectively acknowledging rather than explicitly endorsing sources, and shows how she contests sources for different purposes in different parts of the thesis: in the early part, sources are critiqued as a way to create a gap for her thesis to fill while in the main body of the thesis, she critiques sources as a way to forcefully raise issues with previous theorizing.

Coffin illustrates and summarizes the different rhetorical functions that referencing fulfills in the thesis she examined. In her conclusion, she recommends raising students' awareness of the various rhetorical options for referencing sources and using these to diagnose weaknesses in the students' writing, such as overuse of modes of attribution which directly endorse or contest the claims of other authors, and to offer alternatives. Coffin's classification of referencing functions, along with the general discussion and examples of source use provided in the article as a whole, should prove useful to thesis students in the same and other fields as well as their supervisors or instructors, who can find parallel examples for their own disciplines to use as illustrative material within Coffin's framework.

In "Using the PhD Thesis Introduction as a Heuristic Device for Supporting the Writing of a Thesis," Donohue seeks to describe a thesis introduction in a pedagogically useful and dynamic way, as socially situated action performed by the writer. Donohue examines the introduction (labeled Preface) of the model Film Studies thesis in detail, using visual mapping of the field of knowledge being constructed and analyzing the speech acts and language used to realize these. He first considers what the thesis introduction does, that is, the kinds of communicative acts it performs, such as outlining the structure of the thesis and posing a fundamental question to be answered, and illustrates these with original displays (concept maps) of the introduction as a whole and of selected individual paragraphs. He next considers what the thesis introduction means through a reading of the concept maps and an in-depth analysis of one paragraph of the introduction. The analysis shows

\section{equinoxonline}


the evolving problem-solution structure of the introduction as the author maneuvers to provide a niche for her thesis. Donohue then considers how the introduction does what it does and means what it does, using a process of interrogating the text to foreground its structure by converting the information in each clause into a question whose answer is provided in the next clause. This technique, which focuses on both function and language, makes clear the evolving schema of the thesis introduction - and by projection, the entire thesis - by highlighting the relationships between neighboring clauses. The interrogating-the-text technique is used to analyze the method of development of the introduction in terms of the progression of thematic and new information.

Donohue suggests that the method he illustrates of interrogating the thesis introduction can serve as a heuristic device for projecting the meaning and structure of the entire thesis and ensuring its coherence. He also proposes that visual displays like his concept maps can be useful as heuristic devices to aid in the writing of the thesis, as the author attempts to generate and refine text in relation to a visualization of concepts and their relationships. These two techniques, which can be performed by the thesis student alone or interactively between the thesis supervisor and the student, might be used during the writing of the thesis through multiple drafts, aiding the student to continually refine ideas and revise the thesis text with a clear vision of the functions and relationships of different parts to the whole.

John's article, "The Influence of Revision on First Person Pronoun Use in Dissertation Writing," is based on Master of Arts theses in areas of Applied Linguistics that were written by a group of largely Asian international students studying at a U.K. university. John provides a discussion of the concept of writer identity and offers a model of writer identity within a thesis, showing how thesis writers might use the first person pronoun $(I)$ to establish different aspects of their identity and roles as thesis writers. The thesis writer might use I to signal identity as a person, for giving autobiographical information. In addition, I might be used to indicate the thesis writer's role as Academic: Scholar in presenting, reporting, and commenting on different aspects of the research. A third role for the thesis writer is that of Academic: Organizer, for directing the reader to the organization of the thesis.

John reports first on the overall pattern and variation in the final drafts of 17 theses. Nearly $75 \%$ of the instances of the first person pronoun are in the category of Academic: Scholar, with the remainder split relatively equally between the Academic: Organizer and Person identities. The individual theses vary widely in terms of the extent of use of the first person pronoun, ranging from 2 to 95 instances. John then examines the changes in use of first person

\section{equinoxonline}


pronouns across thesis drafts, looking at additions, deletions, and changes in type of first person pronouns from one draft to the next. In some cases, she suggests alternative revisions that could have portrayed the thesis writer's identity differently. The discussion shows how postgraduate students might gain an increasing knowledge of the function of personal pronouns and how language choices can shape their identity as writers and hence their relationship with readers. It further illustrates how different drafts of a thesis can be used as teaching tools in aiding students to move from a more personal starting point of their thesis to a more scholarly persona as academic.

The Reflections on Practice section of the journal seeks to highlight good practices in relation to published literature on writing theory, research, and pedagogy. In the current issue, Annette Frances Sachtleben, Pat Strauss, and Elizabeth Turner, in "Empowering the Apprentice Academic: Teaching Writing at Postgraduate Level," describe a series of workshops and individual tutorials for postgraduate students developed at Auckland University of Technology by applied linguists. The workshop and tutorial support is aimed at students doing Masters and Doctoral work in Business and Art and Design as well as those writing an exegesis to accompany a final project in Art and Design. To prepare the workshops for the Business students, the applied linguists met with Business colleagues and studied relevant journal articles and theses to find examples of hedging language, verb usage, and the use of discourse markers to clarify the construction of an argument. The course proved popular and useful to students and became a required part of the research support offered to Business postgraduate students. The applied linguists then expanded and adopted their instructional program to work with Art and Design students on both their final project exegeses and their theses. An important part of the support provided occurs in individual tutorials between an applied linguist and a student, based on critique of a 15-page draft of the student's work. In the tutorials, the student functions as the disciplinary expert, with the applied linguist functioning to aid the student to clarify and express meaning. One can imagine a sort of Socratic dialogue in these oneon-one tutorials that might be a suitable context for Donohue's interrogating the text and concept mapping techniques. At present, the applied linguists are experimenting with a combination of face-to-face and online delivery of the materials they have developed, with the challenge of maintaining the valuable one-on-one interaction with students.

In "Reflections on Teaching Discourse Functions Using a Science Thesis," Philip Hubbard illustrates how a thesis in a specific field - in this case, cryobiology - can be mined as a rich source of examples of discourse functions to use in teaching these to postgraduate students. Hubbard shows how he 
used the material in a postgraduate writing course that is one in a sequence offered for international Masters and PhD students who are largely science or engineering majors at Stanford University. Hubbard's exposition provides coverage of discourse functions such as expressing comparison or contrast, intensifying or hedging, and defining in a specific area of biology, as he models a procedure that thesis supervisors and those teaching writing for postgraduate students or advanced professional or academic writing might find useful. His classification and discussion of the examples could be adapted for students in other disciplines by substituting parallel examples from theses in those disciplines. Two of his pedagogical suggestions are to have students themselves look for examples of the various discourse functions in a thesis in their field and to have them examine their own draft thesis chapters for examples of specific discourse markers and functions. In this way, students can connect their thesis writing to authentic examples from other scholars and thesis students in their own field.

This issue's From the e-Sphere section contains two articles on computer analysis that can be applied to postgraduate writing. In the first of these, “Text Analysis by Computer: Using Free Online Resources to Explore Academic Writing," Ylva Berglund Prytz offers a review of freely available electronic corpora and tools for analyzing text in digital form. The online corpora and computer tools can be used for presenting examples as well as for analyzing postgraduate students' draft materials as they are writing the thesis or dissertation. The tools include software for concordancing, that is, searching all instances of a specific word or phrase and showing its contexts; for showing the relative frequency of specific words or phrases in a text; for showing collocates, that is, words which tend to occur in the same context though not necessarily side by side; and for computing general statistics on a text, such as the average length of sentences and the ratio of unique words to repeated words (type/token ratio). Using such tools, students can compare their own evolving thesis text with that of other texts in their field. Berglund Prytz offers a helpful example of different kinds of analysis as applied to an essay written by an English language learner.

In "Semi-Automated Analysis of a Thesis," Oliver Mason and Martha C. Pennington discuss the potential of computer tools for analyzing low-level features in order to characterize thesis chapters and the thesis overall. An illustrative analysis is presented, using the method of Correspondence Analysis, of reporting verb usage in four model theses: one each from Biology (the same one used by Hubbard in this issue), Linguistics, and Film Studies (the same one used by Coffin and Donohue in this issue), and two in Tourism. The analysis points up similarities and differences across chapter types within one thesis and across 
theses that may be related to genre conventions in different disciplines. For example, the analysis shows that the one science thesis has a more distinctive methodology chapter than do the other theses analyzed. The authors suggest the value of this and other kinds of statistical analysis for comparing selected features of student writing, such as thesis drafts, to the same features in a model text, such as a model thesis from the same field.

The New Books section contains a review by Vladimir Žegarac of Dimitra Koutsantoni's Developing Academic Literacies: Understanding Disciplinary Communities' Culture and Rhetoric, a study of the linguistic characteristics of research articles and theses in electronic, electrical, and chemical engineering. Koutsantoni also compares writing in these fields by English and Greek authors and offers pedagogical suggestions for working with postgraduate students on their writing. While arguing that the author might have taken a more critical stance in regard to the existing literature and analytical categories, Žegarac nonetheless finds that the book "makes a useful contribution to understanding academic writing, demonstrates the need for greater promotion of academic literacy, and brings us a few big steps closer to devising better methods for teaching/learning language for academic purposes."

I hope readers of Writing \& Pedagogy - even those who do not teach postgraduate students - find this, the first of our special topics issues, to be both unique and worthwhile, and will learn something of value from it. I also hope readers will share the information in this issue, and the additional resources which the authors describe, with other writing scholars and teachers, with colleagues in other disciplines, and with deans or heads of teaching centers who are in a position to influence policy and practice relating to postgraduate students. At the very least, some of the knowledge contained and the practices described in this issue can help to get a conversation started about thesis writing and how best to support the writing needs of postgraduate students on the many campuses that have not yet seriously begun that conversation; and on the campuses that are already engaged in the conversation, the information in this issue can perhaps add some new perspectives on the areas of language that can be addressed and the ways of doing so. 


\section{Note}

1 In the U.K., New Zealand, and some other countries, the term thesis is reserved for $\mathrm{PhD}$, and dissertation is used at Masters level. In the U.S., both are often referred to as theses, and dissertation is not used for Masters level work but only for Doctoral level work.

\section{References}

Biber, D., Conrad, S., and Leech, G. (2002) Longman Student Grammar of Spoken and Written English. Harlow: Pearson Education Limited.

Biber, D., Conrad, S., and Reppen, R. (1998) Corpus Linguistics: Investigating Language Structure and Use. Cambridge: Cambridge University Press.

Biber, D., Johansson, S., Leech, G., Conrad, S., and Finegan, E. (1999) Longman Grammar of Spoken and Written English. London: Longman.

Carter, M. (2007) Ways of knowing, doing, and writing in the disciplines. CCC 58(3): 385-418.

Carter, R. and McCarthy, M. (2006) Cambridge Grammar of English: A Comprehensive Guide to Spoken and Written English Grammar and Usage. Cambridge: Cambridge University Press.

Dudley-Evans, T. and St. John, M. J. (1998) Developments in English for Specific Purposes: A Multi-disciplinary Approach. Cambridge: Cambridge University Press.

Eggins, S. (1994) An Introduction to Systemic Functional Linguistics. London: Pinter.

Halliday, M. A. K. (1985) Introduction to Functional Grammar. London: Edward Arnold.

Hutchinson, T. and Waters, A. (1987) English for Specific Purposes. Cambridge: Cambridge University Press.

Hyland, K. (2000) Disciplinary Discourses: Social Interaction in Academic Writing. London: Longman.

Hyland, K. (2006) English for Academic Purposes: An Advanced Resource Book. London: Routledge.

Jordan, R. R. (1997) English for Academic Purposes: A Guide and Resource Book for Teachers. Cambridge: Cambridge University Press.

Segal, M. T. and Smart, R. A. (2006) Direct from the Disciplines: Writing Across the Curriculum. Portsmouth, New Hampshire: Boynton-Cook, Heinemann.

Swales, J. M. (1990) Genre Analysis: English in Academic and Research Settings. Cambridge: Cambridge University Press.

Swales, J. M. and Feak, C. (1994) Academic Writing for Graduate Students. Ann Arbor, Michigan: University of Michigan Press.

\section{eevinoxonline}




\section{Upcoming Issues}

We are planning one open topic issue and one special topic issue per year. We are still accepting submissions for the first issue (open topic) of Volume 3 (2011). For best consideration, submit by 30 June 2010. We are especially interested in the following topics for future special topic issues or individual articles in the genres of essay, research, and reflections on practice: Teaching Writing in Elementary School, Teaching Writing in the Disciplines, Teaching Writing Online, Changing Needs for Writing in the Twenty-First Century, Writing Assessment, Education and Professional Development of Writing Teachers. The special topic issues for the next three volumes are:

UPCOMING SPECIAL TOPIC ISSUES

\begin{tabular}{|c|c|c|}
\hline Vol. 2(2) 2010 & Plagiarism in the Academy & In editing \\
\hline Vol. 3(2) 2011 & Multiliteracies & $\begin{array}{l}\text { Guest Editors } \\
\text { Jim Cummins and } \\
\text { Sherry Taylor }\end{array}$ \\
\hline Vol. 4(2) 2012 & $\begin{array}{l}\text { Creativity and Writing and } \\
\text { Pedagogy }\end{array}$ & $\begin{array}{l}\text { Guest Editor } \\
\text { Harriet Millan }\end{array}$ \\
\hline
\end{tabular}

The Plagiarism in the Academy issue is in the final editing stage. The contents and authors of the Multiliteracies issue have been agreed with the Guest Editors, Jim Cummins (Ontario Institute of Studies in Education, University of Toronto, Canada) and Sherry Taylor (University of Western Ontario, Canada). We are seeking contributions for the Creative Writing and Pedagogy issue edited by Harriet Levin Millan (Drexel University, USA).

\section{Call for Contributions to Special Topic Issue, Volume 4(2), Autumn 2012 Creativity and Writing Pedagogy}

Writing \& Pedagogy announces a special topic issue on Creativity and Writing Pedagogy guest-edited by Barnard New Women Poet's Prize winning author, Harriet Levin (Millan), Writing Program Director at Drexel University. The issue aims to present the latest research and practice on creativity as it pertains to writers and writing, which may include theoretical essays and research articles on technology measuring or advancing creativity or on the study of creative methods or practices as these pertain to writing; personal narratives on individual creative writing processes; and reflective practice contributions on teaching creative writing to college age students, adults, or children. The issue aims to break new ground in offering a comprehensive look, both practical and theoretical, at enhancing learners' skills as creative thinkers and writers.

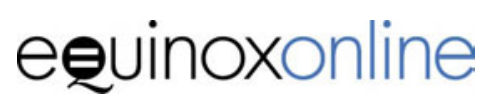


Submit detailed outline or article for consideration by December 1, 2010 to:

Harriet Levin Millan

Director, Writing Program

Drexel University

Department of English and Philosophy-5th floor

MacAlister Hall

33rd and Chestnut Streets

Philadelphia, PA 19104

millanhl@drexel.edu

CONTENTS Volume 2, number 1 (Spring 2010)

\section{Research Matters}

Writing in Late Immersion Biology and History Classes in Hong Kong

Stella Kong, Hong Kong Institute of Education (Hong Kong)

Chained and Confused: Teacher Perceptions of Formulaic Writing in a Virtual Classroom

Amy Alison Lannin and Roy F. Fox, University of Missouri (USA)

Undergraduate Iranian EFL Learners' Use of Writing Strategies

Esmael Abdollahzadeh, University of Tehran (Iran)

\section{Reflections on Practice}

Engaging Future Teachers to Reflect on How Reading and Writing Can Change Lives

Maureen P. Hall and Robert P. Waxler, University of Massachusetts at Dartmouth (USA)

A Refocused Approach to Writing Instruction

Lisa Nazarenko and Gillian Schwarz, University of Vienna (Austria)

\section{From the e-Sphere}

Writing in a Multiliterate Flat World, Part I: Multiliterate Approaches to Writing and Collaboration Through Social Networking Vance Stevens, The Petroleum Institute, Abu Dhabi (UAE)

\section{New Books}

Ernest Morrell, Critical Literacy and Urban Youth: Pedagogies of Access, Dissent, and Liberation

Reviewed by Elaine Richardson, The Ohio University (USA)

Mary Lynch Kennedy and William J. Kennedy, Writing in the Disciplines:

A Reader and Rhetoric for Academic Writers (Sixth Edition)

Reviewed by Mark N. Brock, Carson-Newman College (USA) 
HIGHLIGHTS Volume 2, number 2 (Autumn 2010) Special Topic: Plagiarism in the Academy

\section{Research Matters}

Writing from Sources, Writing from Sentences

Rebecca Moore Howard, Patricia Serviss, and Tanya K. Rodrigue, Syracuse University (USA)

How Do University Students Attempt to Avoid Plagiarism? A Grammatical Analysis of Undergraduate Paraphrasing Strategies

Casey Keck, San Francisco State University (USA)

Addressing Pedagogy on Textual Borrowing: Focus on Instructional Resources Zuzana Tomaš, University of Utah (USA)

Student and Teacher Perceptions of Plagiarism in Academic Writing Nahla Nola Bacha and Rima Bahous, Lebanese American University (Lebanon)

\section{Reflections on Practice}

Teaching Novice Writers Concepts of Academic Honesty and Plagiarism Jane Suzanne Conzett, Margaret Martin, and Madeleine Mitchell, Xavier University (USA)

Preventing Plagiarism: Working with What Works

Mark Lewis Richardson and Tammy Linder

\section{New Books}

Diane Pecorari, Academic Writing and Plagiarism: A Linguistic Analysis Reviewed by Virginia LoCastro, University of Florida (USA) Wendy Sutherland-Smith, Plagiarism, the Internet and Student Learning Reviewed by Miriam Eisenstein Ebsworth, New York University (USA) 